\section{Kritikal at inferensyal na kakayahan sa pagbasa ng mga mag-aaral sa larangan ng Filipino ng Visayas State University}

\author{
Flores, Marievic S. $\$ \\ Department of Teacher Education, Visayas State University, Philippines (marievic.flores@vsu.edu.ph)
}

\begin{tabular}{lll}
$\begin{array}{l}\text { Received: } 30 \text { May } 2020 \\
\text { Available Online: } 14 \text { July 2020 }\end{array}$ & Revised: 15 June 2020 & Accepted: 26 June 2020 \\
\hline
\end{tabular}

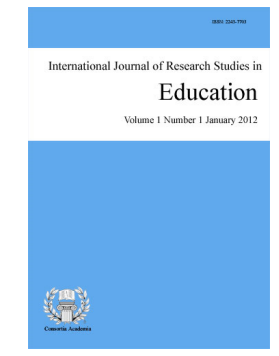

ISSN: 2243-7703 Online ISSN: 2243-7711

OPEN ACCESS

\title{
Abstract
}

Layunin ng pag-aaral na ito ang makilala ang kakayahan ng mga mag-aaral ng Visayas State University na nagpapakadalubahasa sa asignaturang Filipino sa larangan ng pag-unawa ng pagbasa gamit ang tatlong mga hakbang nito. Ginamit sa pag-aaral na ito ang deskriptiv-analitik sa pamamagitan ng purposive sampling. May apat na pu't lima (45) na mga kalahok na pawang mga mag-aaral ng kolehiyo. Anim na mga maikling kwento ang ginamit bilang instrumento ng pag-aaral. At batay sa resulta, mataas ang kabuuang marka ng mga lalaki kaysa sa mga babae. Samantala, ang kakayahan ng mga mag-aaral sa kritikal at inferensiyal na pag-unawa sa hakbang na bago bumasa ay katanggap-tanggap kung saan ang elementong kalinawan ang nangunguna na may deskriptibong napakakatanggap-tanggap. Mataas naman ang kakayahan ng mga mag-aaral sa hakbang na habang nagbabasa na may resultang napakakatanggap-tanggap. At sa hakbang na pagkatapos na binasa ay may resultang katangi-tangi ang kakayahan ng mga kalahok. Habang ang elementong kalinawan ay nangunguna at ang elementong lohikal ang pinakamababang kakayahan. Ang mga mag-aaral sa hakbang na bago ang basa na napabilang sa mababang pamantayan ang nakakuha nang mataas na kakayahan, sinundan ng mataas na pamantayan at ang panghuli ay ang mga mag-aaral sa pamantayan nito. Sa hakbang na habang bumasa, nangunguna ang mga mag-aaral sa mataas na pamantayan, sinundan ng nasa pamantayan lamang nito at mga mag-aaral na nasa mababang pamantayan ang siyang may pinakamababang mean. Sa hakbang pagkatapos bumasa, nangunguna ang mga mag-aaral na nasa mataas na pamantayan, sinundan ng nasa pamantayan at ang may pinakamababang mean ay ang mga mag-aaral na nasa mababang pamantayan. May kaibahan ang kakayahan ng mga mag-aaral sa kasarian at kabuuang marka at walang kaibahan ang kakayahan ng mga mag-aaral sa tatlong hakbang ng pagbasa na kahit tumaas ang marka o kakayahan ng mga kalahok ngunit, hindi masyadong mataas ang pagtaas ng kanilang kakayahan. Ang lohikal na kakayahan sa pag-unawa ay ang pangunahing dahilan kung bakit mababa sa pag-unawa ng kritikal at inferensiyal na kakayahan ng mga mag-aaral.

Keywords: kritikal; inferensyal; hakbang ng pagbasa; deskriptiv-analitik; kabuuang marka; grade point average 


\section{Kritikal at inferensyal na kakayahan sa pagbasa ng mga mag-aaral sa larangan ng Filipino ng Visayas State University}

\section{Introduction}

"Every man who knows how to read has it in his power to magnify himself, to multiply the ways in which he exists, to make his life full, significant and interesting”--- Aldous Huxley, 1894.

Ang pahayag sa unang talata ay nagpapahiwatig sa kahalagahan ng kakayahan ng pag-unawa sa bawat inidibidwal. Ang No Child Left Behind Act of 2001 na inilathala sa Education Week ay naglalayon na magkakaroon ng mataas na kalidad sa pag-unawa ng pagbasa ang mga mag-aaral upang makabuo ng isang de-kalidad na mga mag-aaral. Ang pagbabasa ay isang perceptual at isang kognitibong proseso sa kamalayan ng isang mambabasa. Ito ay isang proseso kung saan nabibigyang linaw nito ang mga bagay-bagay na malabo para sa isang indibidwal. Bukod dito, sa gawaing ito, ang isang bihasang mambabasa ay dapat na gumamit ng pandama, syntactic, semantiko, at pragmatik na impormasyon upang maisagawa ang gawain. Ang iba't ibang mga mapagkukunan ng impormasyon ay lumilitaw na nakikipag-ugnay sa maraming mga kumplikadong kaparaanan sa panahon ng proseso ng pagbasa.

Nangagahulugan lamang na ang isang mababasa ay kailangang dumaan sa proseso ng pagbabasa upang higit niyang maunawaan ang teksto at nilalaman ng isang babasahin.Sa gawaing ito, mas nabibigyang halaga at sapat na pang-unawa ng isang indibidwal sa paglalahad ng sariling intepretasyon sa nilalaman ng teksto. Dahil isa sa mga suliraning kinakaharap sa panahon ng kasalukuyan an gang pagbabasa nang walang pag-iintindi sa tekstong binasa.

Sa katunayan ang resulta ng mga pag-aaral nina Pabuaya (2014), Monter (2016), Villacruz (2016), Yamson (2017) at marami pang iba na halos pareho ang kakayahan ng mga mag-aaral sa kritikal na pag-unawa na nasa mababang pamantayan. Ang resulta ng mga pag-aaral sa mga mananaliksik ay nanatiling matinding suliranin sa kasalukuyan. Ito ang dahilan kung bakit nahikayat ang mananaliksik na suriin ang kakayahan ng pag-unawa ng mga mag-aaral na nagpapakadalubhasa sa Filipino ng Visayas State University (VSU). Tulad ng ibang mananaliksik na sa ilang taong pagtuturo, ang kakayahan ng pag-unawa ng mga mag-aaral lalo na sa kritikal at inferensiyal na lebel ay nangangailangan ng atensiyon ang mga mag-aaral. Ito ay isa sa mga suliranin ng mananaliksik sapagkat ang kakayahang ito at dapat malinang ng bawat mag-aaral lalo na nasa kolehiyo.

Ayon kay Tizon (2013) hindi sapat na marunong lamang ang mga mag-aaral na magbasa sa mga salitang nakalimbag, kailangan may kakayahan siyang makapag interpreta sa tunay na kahulugan ng binasa. Ganoon din ang pahayag ni Cekiso (2012) na nagsabing mag-isip ng mga estratehiya upang makilala ang pagkamalikhain at pagkakritikal na mag-isip ang mga mag-aaral. Napakahalagang pagtuunan ng mga guro ang kakayahang pag-unawa at malinang ng bawat mag-aaral sapagkat tulay ito sa pagkakaroon ng matagumpay na academic performance.

Sa mga nakaraang taon, maraming mananaliksik na binigyang pokus ang kakayahan ng pag-unawa sa pagbasa ng mga mag-aaral. Isa itong makabuluhan dahil paraan ito upang matulungan ang mga pangangailangan ng mga mag-aaral. Ngunit sa kasalukuyan patuloy pa rin ang mga pag-aaral na ito kung saan nanatili pa ring pinagtuunan ng pansin ang komprehensiyon ng mga mag-aaral lalo na sa antas na integratibo, kritikal at pagkamalikhain (Medina, 2011; Antoniou at Souvignier, 2007). Ang kakulangan sa pag-unawa sa mga elemento ng pagbasa ay isa sa mga kadahilanan sa patuloy na pagbaba sa kakayahan ng pag-unawa sa kritikal at inferensiyal na mga mag-aaral na siyang dahilan kung bakit binuo ang pag-aaral na ito. Ang estratehiya ng pagbasa o pagkilala sa kakayahan ng pag-unawa ay nangangailangan ng pagplano at pag-analisa sa mga uri at klase na mga mag-aaral. 
Kaugnay nito ipinaliwanag ni Yamson (2017), na ang kritikal na kakayahang ng pag-unawa ay naging suliranin din sa ibang mga tagahubog na nangangailangan ng atensiyon. Binanggit ni Monter (2015), ang kakayahang pag-unawang kritikal at inferensiyal ng mga mag-aaral ay isa sa mga suliranin ng mga guro sa kasalukuyan. Marami sa mga mag-aaral ay kulang ang interes sa mga gawaing pagbasa. Ito ang dahilan kung bakit mababa ang kanilang kakayahan sa pag-unawa lalo na sa mga nangangailangan nang mataas na lebel na pag-aanalisa.

Sa pag-aaral ni Kispal (2008) nakakuha ng mababang antas ng kakayahang ang kanyang mga mag-aaral sa kritikal at inferensiyal na kakayahan sa pag-unawa sa pagbasa. Ang pahayag nina Yamson (2017) at Monter (2015) ay kaugnay sa suliranin ng mananaliksik sa pag-unawa ng pagbasa sa kanyang mga mag-aaral. Maituturing niya itong isang malaking suliranin sapagkat ang mga katanungan na nangangailangan ng integratibo sa sarili at malikhaing pag-iisip ay hindi ginamit ng kanyang mga mag-aaral sa tuwing hinihingi ang mga ganitong kasagutan.

\subsection{Kritikal na pag-unawa}

Ang kakayahang ito ay ang pagbibigay ng reaksyon, pag-iisip na masaklaw at malawak pagbibigay ng pagkakaiba at pagkakatulad, pagdama sa pananaw ng may-akda, pag-unawa sa mga impresyon o kakintalang nadama, pagkilala sa pagkakaroon o kawalan ng kaisahan ng diwa ng mga pangungusap, pagkilala sa pagkakaugnay-ugnay ng mga pangungusap sa isang talataan, pagtatalakayan tungkol sa mabubuting katangian ng kwento at pagpapasya tungkol sa kabisaan ng paglalahad. Ito ang kakayahang maintindihan o maunawaan ang kaakibat na kahulugan ng mga salitang nakalimbag.

Ang kritikal na pag-unawa ay nangangailangan ng masusing pag-aaral sa paksang tinatalakay ng awtor. Ang kasanayan sa pagbasa na may pag-unawa ay mahalaga sa ganitong gawain (Villacruz, 2016). Ito rin ay may kakayahang magbigay ng paliwanag sa isang tumpak na sitwasyon. Tumutukoy rin ito sa kakayahang mag-aanalisa sa kabuang sitwasyon o isyu o kaya'y mula sa nabasang teksto. Matatawag na isang kritikal na mag-isip ang isang mag-aaral kung epektibo ang kanyang pagbibigay aanalisasyon, magpaliwanag, tama ang pagbibigay interpretasyon. Ipinaliwanag pa madali niyang naiugnay ang mga nakaraan sa kasalukuyang sitwasyon.

Tungkulin ng guro ay tagahasik tagapangalaga ng karunungan at tagapamatnubay sa bawat indibidwal. Mula sa mga tungkuling ito makikita ang kompleks na gawain ng isang guro. Ang pagkatuto ay isang paraan upang mahugot ang kaalaman na nagtuturo sa tao na magkaroon ng kanais-nais na kalooban at kapaki-pakinabang na mamamayan sa lipunan. Sa panahon na tinatawag na kompetisyon ng globalisasyon kailangan magtaglay ng ganitong kakayahan. Iminungkahi nina Monter (2016), Tagalog (2015), Pabuaya (2014) at Pia (2011) na ang guro ay hindi dapat tumigil sa pagbibigay ng mga gawaing makapagpapaunlad sa kakayahan ng mga mag-aaral lalo na sa kasalukuyan na ang daigdig ay puno ng mga pagbabago. Ang mga pagbabagong ito ay nakapagdudulot ng hindi magandang resulta sa kakayahan ng mga mag-aaral.

Sa pag-aaral nina Monter (2016), Tagalog (2015), at Pabuaya (2014) naipakita na parehong nasa mababang antas na kakayahan ang mga mag-aaral sa kritikal na pag-unawa. Ang resultang ito ay kailangan hindi dapat ipagkawalang bahala ng mga gurong may hangarin makabuo ng isang kwalidad ng mga mag-aaral. Ang kakayan ng pag-unawa sa pagbasa ay isang napakahalagang puhunan sa mga kakayahang pangka-akademiko. Marami sa mga mag-aaral ay mahina sa paglalahad na nangangailangan ng mga aplikasyong mula sa sariling pag-unawa. May nagsabing marami sa kanilang mag-aaral ay hindi sinanay ang kritikal na pag-unawa sa mga nabasa. Isa totoo maraming suliraning ang kinaharap ng mga guro sa usaping pagbabasa kaya patuloy na naglulunsad ng mga programa ang DepEd upang masolusyunan ang suliraning ito. Isa sa mga programa ay ang Philippine Informal Reading na sinusukat dito ang antas ng pag-unawa ng mga mag-aaral. 


\subsection{Inferensiyal na kakayahan}

Ang inferensiyal na kakayahan ay tumutukoy sa kakayahan ng mga mag-aaral makilala ang nais iparating ng may-akda sa tekstong nabasa at may kakayahang maiugnay ang mga pangyayari sa teksto sa mga nauunang kaalaman ng mga mag-aaral (Villacruz, 2016). Sa kakayahang ito ay nangangaingalan ng masusing pagtingin sa anggulong tinatalakay ng sumulat. Sa antas ng pagbasang ito, nangangailangan ang mambabasa ng malawak na kaalaman sa paksang binabasa upang masuri at makabuo ng matatag na pananaw. Maaaring makatulong sa bumabasa ang larangang ito gaya ng sino ang sumulat; ang paninindigan nito; mga karanasan; at mga bagay na may kinalaman sa sumulat.

Iminungkahi nina Green at Roth (2013) ipagpatuloy ng mga guro ang paghahamon sa mga mag-aaral na magpapaliwanag sa kanilang mga nauunang kaalaman sa paksa upang makapagbigay ng mga hinuha sa mga nabasang teksto. Mula naman sa pamanahong papel nina Rusaban et al. (2017) ibinahagi na ang inferensiyal na kakayahang sa pag-unawa ay ang pagbibigay ng tunay na kahulugang nakatago sa mga salita o kahulugang mula sa isang akdang nabasa. Ang kakayahang ito a napabilang sa mataas na antas na dimensiyon sa pagbasa. Ayon naman kay Hirsch (2003) na binanggit ni Cekiso (2012) ang kakayang inferensiyal na pag-unawa sa pagbasa kakayahang nagtataglay ng mataas na lebel sa bokabularyo, kakayahang magkapag-interpreta sa mga sitwasyon at kakayahang makapag-uugnay sa mga nakaraan pangyayari kaugnay sa kasalukuyan. Iminungkahi ni Cekiso (2012) hikayatin ang mga mag-aaral na makapagpaliwanag sa kanilang mga kaaalaman huwag hahayaang hanggang sa literal lamang ang kanilang pagpapahayag.

Ang inferensiyal na kakayahan sa pag-unawa ay napakahalagang taglayin ng bawat mag-aaral. Sa kakayahang ito makakaugnay ang mga mag-aaral sa kanilang mga karanasan at sa mga nabasang teksto sa mga kasalukuyang sitwasyon. Ayon kina Green at Roth (2013) ang kakayahang makabuo ng inferensiyal na pag-unawa ay isang malaking kasanayan na makabuluhan ang pag-unawa. Ito ay sinuportahan nina Graham at Harris (2012) at Haque (2010) na naniniwalang ang mga mag-aaral na magkakaroon ng inferensiyal na kakayahan sa pag-unawa ay susi at tulay na maging matagumpay sa pagkuha ng tumpak at angkop na mensahe ng may-akda.

Maraming mga dahilang sa kakulungan ng kakayahan ng mga mag-aaral sa pag-unawang inferensiyal. Isa sa mga dahilan dito ay kakukulangan ng mga pagsasanay na nangangailangan ng mga pagpapaliwanag at pagpapalawak sa mga naunawaan. Marami sa mga guro ay mga literal na pagtatanong lamang kaysa sa inferensiyal na tanong (Pia, 2011). Sa hakbang nab ago ang basa, magkakaroon dito ng prediksyon ang mambabasa sa binasa ng kwento sa pamamagitan ng pag-aanalisa ng pamagat o kaya's larawan sa isang aklat. Ang pangalawang hakbangin ang reaksiyon at pagtuklas (responding and exploring) sa paraang ito habang binabasa ng mambabasa ang teksto maiuugnay niya ang nilalaman sa teksto sa mga katanungang ibinigay ng guro. Sa bahaging ito maaaring maiuugnay ng mambabasa sa kanyang sarili ang mga papel na ginagampanan ng mga tauhan sa kwento. Sa bahagi ring ito malalaman ng mambabasa kung tama ang kanyang prediksiyon.

Ang huling hakbangin ay ang aplikasyon o pagkatapos bumasa. Sa bahaging ito magkakaroon ng refleksiyon ang mambabasa sa mensahe ng binasa sa pamamagitan ng paggawa ng bagong wakas ng kwento o kaya'y bubuo o guguhit ng isang larawan na kumakatawan sa kahulugan ng kwento. Ipinaliwanag din na ang pagbasa ay isang kompleks na interaksiyon sa teksto at mambabasa. Sa pagbasa mabubuo ng mambabasa ang mga naunang kaalaman (prior knowledge), maiugnay ang mga karanasan habang binabasa ang teksto at magkakaroon ng integrasyon sa lipunan ang mga nababasang teksto.

Ang pagbasa ay isa sa mga makrong kasanayan na itinuturing na napakahalaga sa bawat tao at sa lipunan. Ang pagbasa ay may maraming kompetensi. Isa na rito ang tinatawag na reader's comprehension na binigyan diin dito ang mga naunang kaalaman (prior knowledge) ng mga mambabasa. Ibang kompetensi ay ang self-monitoring na inaasahang malilinang ang kakayahan ng mga na makapredik sa nilalaman ng teksto. At ang ibang kompetensi ay ebalwatib na komprehensiyon na kung saan kailangan malinang at mapaunlad ng mga 
mag-aaral ang paghuhusga, pag-aanalisa, pagsusuri sa katangian ng bawat karakter ng kwento, pagpapahalaga at pagbibigay refleskiyon sa sarili, at pagsusuri sa ipinabatid sa teksto.

Ang pag-unawa ay ang kauna-unahang layunin ng pagbasa. Ang pananaliksik na ito ay napakahalaga upang magsisilbing batayan ng mga guro kung anong uri ng babasahin at pagtataya ang dapat ibigay sa kanyang mga mag-aaral ganoon din ang angkop na interbensiyon sa mga mag-aaral na medyur sa Filipino na nahihirapan sa mga kritikal at inferensiyal na pag-unawa sa pagbasa. Higit sa lahat ang pag-aaral na ito ay makapagdudulot ng kamulatan na ang kakayahang ng pag-unawa sa mataas na lebel na dimensiyon ay makatutulong sa pagpapataas ng kalidad ng bawat mag-aaral.

Naniniwala ang mananaliksik na ang pag-aaral na ito ay kapaki-pakinabang hindi lamang sa mananaliksik at sa kanyang mga mag-aaral kundi pati na rin sa mga gurong nagtuturo sa panitikan at magsisilbi rin itong kasagutan sa mga kadalasang suliranin ng mga guro tungkol sa kakayahan ng pag-unawa ng mga mag-aral sa pagbasa.Ang nabuong awtput sa pag-aaral na ito ay maging makabuluhan para sa kapakanan ng mga mag-aaral.

\subsection{Paglalahad ng suliranin}

Sinuri ng pag-aaral na ito ang kritikal at inferensyal na kakayahan sa pagbasa ng mga mag-aaral ng Visayas State University lungsod ng Baybay. Sinagot ng pag-aaral na ito ang mga sumusunod na suliranin:

$>\quad$ Ano ang profayl ng mga mag-aaral nagpapakadalubhasa sa Filipino ng VSU ayon sa mga sumusunod: Kasarian; at Kabuuang Marka?

$>\quad$ Ano ang antas ng kakayahan ng mga kalahok sa pagbasa ayon sa sumusunod na elemento ng pag-unawa: katumpakan (accuracy); kalinawan (clarity); nilalaman (precision); komplex (depth); kaugnayan (depth); at lohikal (logic)?

$>\quad$ Ano ang kakayahan ng mga mag-aaral bago ang pagbasa (pre-reading), reaksiyon at eksploring (during reading) at aplikasyon (post/after reading) batay sa Grade Point Average?

$>\quad$ May kaibahan ba ang kakayahan ng mga mag-aaral ayon sa sumusunod: kasarian; Kabuuang Marka o Grade Point Average; at Hakbang o stages reading?

$>\quad$ Anong awtput ang maimumungkahi batay sa resulta ng pag-aaral?

\section{Disenyo ng pag-aaral at pamamaraan}

Ginamit sa pag-aaral na ito ang deskriptiv-analitik sa pamamagitan ng purposive sampling na kung saan inalam dito ang kakayahan sa pag-unawa ng binasa ng mga mag-aaral ng Visayas State University na nagpapakadalubhasa sa larangan ng Filipino. Ang deskriptiv-analitik ay isang disenyo ng pangangalap ng mga datos at impormasyon hinggil sa mga salik o faktors na kaugnay ng paksa ng pananaliksik. Sa pagkilala ng kakayahan ng mga kalahok ginamit ang rubric nina Paul at Elder (2009) para sa kritikal at inferensiyal na pag-unawa. Sa profile ng mga kalahok, kasarian at kabuuang marka o grade point average, bilang ng madalas at ang bahagdan ang ginamit ng mananaliksik. Ang pamantayan (mean) ang batayan sa pagkilala ng pagkakritikal at inferensiyal na kakayahan ng pag-unasa sa pagbasa mga mag-aaral sa ng Visayas State University na nagpapakadalubhasa sa larangan ng Filipino.

\section{Mga resulta at pagtatalakay}

Sinuri sa kabanatang ito ang kakayahan ng mga mag-aaral sa pag-unawa batay sa tatlong hakbang ng pagbasa ang bago ang pagbasa (pre-reading), reaksiyon at eskploring (during reading) at aplikasyon (post/after reading). 
Flores, M. S.

\section{Talahanayan 1}

Profile ng mga mag-aaral ayon sa kasarian at akademikong performance

\begin{tabular}{lcccccc}
\hline \multirow{3}{*}{ Gender } & \multicolumn{7}{c}{ Performance } \\
\cline { 2 - 7 } & \multicolumn{2}{c}{ Above average } & \multicolumn{2}{c}{ Average } & \multicolumn{2}{c}{ Below average } \\
\cline { 2 - 7 } & $n$ & 22.20 & 4 & 44.40 & 3 & 33.30 \\
\hline Babae & 2 & 1 & 16.70 & 2 & 33.30 \\
Lalaki & 3 & 50.00 & 1 & & \\
\hline
\end{tabular}

Ipinakita sa unag talahanayan na mas mataas ang kabuuang marka o Grade Point Average ng mga lalaki kaysa sa mga babae. Sa katunayan ipinakita sa talahanayan na may 50.00\% na mga lalaki ang napabilang sa mataas na pamantayan. Nangangahulugan na mas matalas ang kaisipan ng mga lalaki kaysa mga babae. Sa katunayan batay sa personal na karanasan ng mananaliksik ang mga babae ay isinasapuso muna ang nilalaman ng binasa bago sinasaisip kung saan maaring apektado ang kanilang pag-unawa sa teksto sapagkat agad silang madadala sa kanilang emosyon o nararamdaman. Hindi tulad ng mga lalaki na inaalisa muna ang mga pangyayari sa nabasa o napanood bago magbigay ng reaksiyon.

Kaugnay nito ipinahayag ni Wallace (2007) na ang mga lalaki ay nangunguna sa mga entrance exam sa kolehiyo kaysa sa mga babae. Mas mataas ang IQ ng mga lalaking mag-aaral sa sekundarya kumpara sa mga babae. Natuklasan na ang mga lalaking mag-aaral sa kolehiyo ng Malaysia mas nangunguna ang mga lalaki sa mga gawaing problem solving Natuklasan din nila na ang mga babaeng mag-aaral ay nangunguna sa mga gawaing nangangailangan ng pagsasaulo o memorization. Ang resultang ito at ang mga ni Wallace (2007) na natuklasan na ang mga mag-aaral na babae ay nangunguna sa lahat ng mga asignatura pasulat man at pasalita. Ang mga babae ay laging positibo sa anumang mga kabiguan. Laging naghahanap ng paraan para magtagumpay sa mga ginagawa. Samantalang ang mga lalaki ay mahina ang kalooban sa tuwing mabigo na ito ang dahilan kung bakit mababa ang kanilang marka. Dagdag pa nila, ang mga lalaki ay walang pakialam sa matataas na marka.

\section{Talahanayan 2}

Antas ng kakayahan sa pagbasa

\begin{tabular}{|c|c|c|c|c|c|c|c|c|c|}
\hline \multirow{3}{*}{$\begin{array}{c}\text { Standards } \\
\text { and } \\
\text { elements }\end{array}$} & \multicolumn{9}{|c|}{ Experimental stages in reading } \\
\hline & \multicolumn{3}{|c|}{ Pre-reading } & \multicolumn{3}{|c|}{ During reading } & \multicolumn{3}{|c|}{ Post-reading } \\
\hline & Mean & $S D$ & Performance & Mean & $S D$ & Performance & Mean & $S D$ & Performance \\
\hline Accuracy & 2.48 & 026 & $\mathrm{~S}$ & 3.00 & 0.36 & $\mathrm{VS}$ & 3.64 & 0.39 & $\mathrm{O}$ \\
\hline Clarity & 2.72 & 0.24 & VS & 3.08 & 0.32 & VS & 3.72 & 0.37 & $\mathrm{O}$ \\
\hline Precision & 2.43 & 0.24 & $\mathrm{~S}$ & 3.04 & 0.26 & VS & 3.42 & 0.30 & $\mathrm{O}$ \\
\hline Depth & 2.54 & 0.24 & $\mathrm{~S}$ & 3.06 & 0.30 & VS & 3.64 & 0.35 & $\mathrm{O}$ \\
\hline Relevance & 2.49 & 0.31 & S & 3.02 & 0.35 & VS & 3.65 & 0.36 & $\mathrm{O}$ \\
\hline Logic & 2.31 & 0.31 & S & 2.94 & 0.54 & VS & 3.02 & 0.28 & VS \\
\hline Overall & 2.49 & 0.26 & $\mathrm{~S}$ & 3.02 & 0.36 & VS & 3.51 & 0.34 & $\mathrm{O}$ \\
\hline
\end{tabular}

Note. Performance: Poor (P), Satisfactory (S), Very satisfactory (VS), and Outstanding (O).

$1.0-1.7=\mathrm{P}, 1.8-2.5=\mathrm{S}, 2.6-3.3=\mathrm{VS}$, and $3.4-4.0=\mathrm{O}$.

Inilahad sa ikalawang talahanayan na ang kakayahan ng mga mag-aaral sa kritikal at inferensiyal na pag-unawa sa hakbanging bago ang pagbasa ay may 2.49 na mean o katanggap-tanggap kung saan ang elementong kalinawan ang nangunguna na may deskriptibong napakakatanggap-tanggap. Samantala, mataas ang performans ng mga mag-aaral sa hakbanging habang bumasa. Sa katanuyan, napakakatanggap-tanggap ang nakuhang deksripsiyon nito. At sa hakbanging pagkatapos bumasa ay katangi-tangi ang performans ng mga kalahok. Mapapansin ang elementong kalinawan ay nangunguna sa lahat ng hakbangin. Sa katunayan sa bago ang basa o pre-reading may 2.72 mean (very satisfactory), sa habang bumasa, may 3.08 na mean (very satisfactory) at sa pagkatapos bumasa may 3.72 ang mean (outstanding) ang nakuha ng mga mag-aaral. Kahit pawang napakakatanggap-tanggap ang nakuha ng mga kalahok sa anim na elemento pero mapapansin na ito ay may pinakamataas na mean at ganoon din sa hakbang bago bumasa.

Malinaw rin sa resulta na tatlong hakbang ng pagbasa ang elementong logic ay may pinamakamababang mean. Kahit katanggap-tanggap ang kadalasang nakuhang deskripsiyon sa anim na elemento sa bago ang basa 
ngunit ito naman ang may pinakamababang mean (2.31). Ganoon din sa habang bumasa na may 2.94 mean lamang at sa pagkatapos bumasa ay napakakatanggap-tanggap lamang ang nakuhang performans ng mga kalahok. Ang resulta ay nagpapahiwatig na kahit pamagat pa lamang ang nabasa ng mga mag-aaral medyo may kakayahan na silang maiugnay ang pamagat sa posibling nilalaman ng kwento. Ito ay nagpapatunay sa kanilang nakuhang mean sa elementong clarity kahit hindi masyadong mataas ang kanilang nakuha kumpara sa ibang stages ng pagbasa nagpapahiwatig pa rin ito ng kanilang kahusayan na kailangan lamang pang linangin.

Maiugnay ang resultang ito sa pahayag nina Flippo at Schumm (2009) na nagsabing may mga mag-aaral na magaling maghihinuha sa mga pangyayari sa pamamagitan ng pagsisiyasat sa pamagat lalo na ang mga babae. Isa sa mga dahilan kung bakit magaling silang mag-uugnay sa nilalaman ay dahil sa pagkahilig nito sa panonood ng mga pelikula. Ang resultang inilahad sa ikalawang talahanayan ay nagpapahiwatig lamang na ang mga gawaing nangangailangan ng mataas na lebel na pag-iisip ay kailangan pagtuunan ng pansin ng mga guro. Ang kakayahang ito ay susi upang magtagumpay ang mga mag-aaral sa mithiin ng programa ng $\mathrm{K}$ to 12 na makabuo ng isang 21 st century skills na mga mag-aaral kung saan ang kakayahan ng kritikal na pag-iisip ay isa sa mga komponent ng 4C's.

Sa during reading at post reading maiugnay naman ang pahayag nina Pabuaya (2014) na madaling maisapuso ng mga mag-aaral ang kwentong melodrama, pampamilya, pag-ibig at suliraning panlipunan dahil posibling ang uri ng kwentong ito ay personal na naranasan na mga mag-aaral na naghahangad na pagdating ng panahon ay maging kasiya-siya rin ang kanilang buhay. Ito marahil ang dahilan kung bakit parehong mataas ang kanilang kakayahan sa elementong clarity sapagkat ang clarity ay tumutukoy sa paglalahad ng makakatohanang pangyayari sa kwento.

Ang logic ay nakakuha ng pinakamababang iskor sa tatlong stages ng pagbasa. Ipinakita lamang dito na ang mga kalahok ay nangangailangan ng atensiyon sa mga gawaing nangangailangan na lohikal na pag-iisip. Mga gawaing ginagamitan ng mga matinding pag-iisip upang makuha ang tumpak na kasagutan. Nagpapahiwatig lamang ito na ang mga kritikal o lohikal na kakayahan ng pag-unawa ng mga mag-aaral ay isa sa mga suliranin na kailangan bigyang atensiyon ng bawat tagahubog. Ganoon din sa resulta ng pag-aaral nina Monter (2016), Tagalog (2015), Pabuaya (2014), at Pelegrino (2010) naging suliranin din sa kanila ang kakayahang kritikal na pag-iisip sapagkat parehong bahagya lamang ang nakuhang kakayahan ng mga mag-aaral sa pag-unawa.

\section{Talahanayan 3}

Kakayahan ng mag-aaral bago ang pagbasa, reaksiyon at eskploring, at aplikasyon batay sa GPA

\begin{tabular}{lccccccc}
\hline \multirow{2}{*}{ Variables } & \multicolumn{2}{c}{ Pre-reading } & \multicolumn{2}{c}{ During reading } & \multicolumn{2}{c}{ Post-reading } \\
\cline { 2 - 7 } & Mean & $S D$ & Mean & SD & Mean & SD \\
\hline Below average & 2.58 & 0.17 & 2.79 & 0.44 & 3.31 & 0.57 \\
Average & 2.41 & 0.32 & 3.10 & 0.32 & 3.51 & 0.12 \\
Above average & 2.49 & 0.19 & 3.18 & 0.13 & 3.72 & 0.13 \\
& Overall & 2.49 & 0.23 & 3.02 & 0.30 & 3.51 & 0.27 \\
\hline
\end{tabular}

Note. Performance: Poor (P), Satisfactory (S), Very satisfactory (VS), and Outstanding (O)

$1.0-1.7=\mathrm{P}, 1.8-2.5=\mathrm{S}, 2.6-3.3=\mathrm{VS}$, and 3.4-4.0 $=\mathrm{O}$.

Inilahad sa ikatlong talahanayan na sa bago ang basa, ang mga mag-aaral na napabilang sa mababang pamantayan ang nakakuha nang mataas na kakayahan na may 2.58 na mean. Ito ay sinundan ng mataas na pamantayan (3.51) at ang panghuli ay ang mga mag-aaral na napabilang sa pamantayan na may 2.41 na mean. Sa habang bumasa, nangunguna naman ang mga mag-aaral na napabilang sa mataas na pamantayan. Sa katunayan 3.18 ang nakuhang mean at sinundan ng mga mag-aaral na nasa pamantayan lamang na may 3.10 na mean at ang mga mag-aaral na nasa mababang pamantayan ay may pinakamababang mean (2.79). Ganoon din matapos ang pagbasa, nangunguna rin ang mga mag-aaral na nasa mataas na pamantayan, sinundan ng mga mag-aaral na nasa pamantayan at ang may pinakamababang mean ay ang mga mag-aaral na nasa mababang pamantayan.

Nangangahulugan itong nakabebentahi ang mga mag-aaral na napabilang sa mataas na pamantayan sapagkat makikita sa resulta na nangunguna sila sa mga gawain bukod sa bago ang basa. Ang matatalinong mag-aaral ay 
malaki ang pagkakataong na makapagbigay ng mga kritikal na ideya tulad ng pagbibigay ng sariling reaksyon tungkol sa mga kaisipang natutuhan o sa akdang nabasa at makapagbigay ng tumpak na paghatol at pagbibigay-pansin sa mga sitwasyon ibinigay. Ang resulta ay nagpapahiwatig na kung ang isang mag-aaral ay may kahinaan sa lohikal na pag-unawa apektado ang kanyang kakayahan sa kritikal at inferensiyal na pag-unawa. Sa pag-aaral ni Pabuaya (2014) natuklasang ang mga mag-aaral na napabilang sa above average ang nangunguna sa mga gawaing nangangailangan ng pagsanib ng mga kaisipan sa mga nabasa sa mga karanasan sa buhay.

Nagpapahiwatig lamang ito na ang mga mag-aaral na napabilang sa mataas na pamantayan ay may kakayahang makapag-unawa ng kritikal at pagkamalikhain sa mga sitwasyon ibibigay ng mga guro. Nangangahulugan na ang mga mag-aaral na nasa mababang pamantayan ay pagtuuunan pansin sa pamamagitan ng mga inobasyon upang mapaunlad at malinang ang kanilang kakayahan sa pag-unawa.

\section{Talahanayan 4}

Kaibahan ng kakayahan ng mga mag-aaral ayon sa kasarian, GPA at phases of reading

\begin{tabular}{lcccccc}
\hline \multicolumn{1}{c}{ Source } & $\begin{array}{c}\text { Type III } \\
\text { Sum of } \\
\text { Squares }\end{array}$ & $d f$ & $\begin{array}{c}\text { Mean } \\
\text { Square }\end{array}$ & $F$ & Sig. & $\begin{array}{c}\text { Partial Eta } \\
\text { Squared }\end{array}$ \\
\hline Corrected Model & $.259^{\mathrm{a}}$ & 17 & .02 & 1.31 & .26 & .45 \\
Intercept & 292.603 & 1 & 292.60 & 25207.62 & .00 & 1.00 \\
Academic Performance & .166 & 2 & .08 & 7.13 & $.00 \mathrm{~s}$ & .35 \\
Sex & .064 & 1 & .06 & 5.53 & $.03 \mathrm{~s}$ & .17 \\
Phases of Reading & .037 & 2 & .02 & 1.58 & .22 & .10 \\
Performance * Sex & .025 & 2 & .01 & 1.08 & .35 & .07 \\
Performance * Phase & .020 & 4 & .00 & .42 & .79 & .06 \\
Sex * Phase & .006 & 2 & .00 & .26 & .77 & .02 \\
Performance * Sex * Phase & .019 & 4 & .00 & .40 & .81 & .06 \\
Error & .313 & 27 & .01 & & & \\
Total & 360.068 & 45 & & & & \\
Corrected Total & .572 & 44 & & & &
\end{tabular}

Note. a. R Squared $=.452($ Adjusted R Squared $=.107)$

Ang resultang inilahad sa ikaapat na talahanayan ay nagpapakita na may kaibahan o kaugnayan ang kakayahan ng mga kalahok sa kanilang grade point average at kasarian. Inilahad sa talahanayang ito na ang akademikong performans o grade point average ay may kaugnayan sa kakayahan ng pag-unawa sa pagbasa. Ipinakita rito na ang mga mag-aaral na may mataas na marka ay mataas din ang kanilang kakayahan sa mga gawaing nangangailangan ng kritikal at pagkamalikhain na pag-iisip. At walang kaibahan ang kakayahan ng mga mag-aaral sa tatlong hakbang na pagbasa sapagkat makikita sa talahanayan 4 na kahit tumaas ang marka o kakayahan ng mga kalahok ngunit hindi masyadong mataas ang pagtaas ng kanilang kakayahan.

Ipinakita sa resultang ito na may kaibahan o kaugnayan ang hakbangin ng pagbasa sa pag-unawa at pagkamalikhain at pagkakritikal ng mga mag-aaral sa pag-unawa. Ipinakita rito na ang mga mag-aaral ay makabuo ng isang maganda at tumpak na pag-unawa sa hakbang matapos ang pagbasa. Nagpapahiwatig ito ang mga magagaling na mga mag-aaral ang mangunguna sa pagkakritikal at pagkamalikhaing pag-unawa at sa tatlong hakbangin ng pagbasa ang pagkatapos bumasa ang nakakuha nang pinakamataas na mean. Ibig sabihin nangunguna ang kakayahan ng mga mga-aaral sa hakbangin na pagkatapos bumasa at sinundan naman ito ng hakbanging habang bumasa. Samanatala, ang may pinakamababang mean na nakakuha ng 2.49 ay ang hakabang nab ago bumasa.

Ipinakita sa resultang ito na sa mga hakbangin ng pagbasa ang pagkatapos bumasa ay epektibong paraan sa pagpapalinang ng pagkakritikal ng mga mag-aaral pagkuha at pag-isip ng mga sitwasyon na tumpak sa hinihingi sapagkat sa bahaging ito ay lubos na naunawaan ng mga mag-aaral ang nilalaman ng teksong nabasa. Kung saan sa bahaging ito madaling maiugnay ng mga mambabasa ang mga pangyayari sa kwento sa bagong karanasan sa tunay na buhay. 
Binigyan-linaw rin ng talahanayan na may kaibahan ang kasarian sa akademikong performance ng mga mag-aaral. Inilahad sa mga naunang resulta na mas mataas ang akademikong performance ng mga lalaki kumpara sa mga babae. Ang resultang ito ay may kaugnayan sa resulta ni Monter (2016) na lumabas sa kanyang pagsusuri na may mataas na kakayahan ang mga lalaki sa mga gawaing nangangailangan ng mga malikhaing pag-iisip. Ganoon din ang pahayag ni Kurtz (2007) na nagsabing sa mga akademikong gawain laging nangunguna ang mga lalaki. Ang naging problema lamang ay kulang sila sa sipag at tiyaga na magbubusisi sa mga aralin, na ito ang dahilan kung bakit malamangan sila sa mga babaeng mag-aaral. Iminungkahi ni Kurtz (2007) huwag ipagwalang bahala ng mga guro ang obserbasyong ito.

Mapapansin na maraming guro na nagsabing naunawaan nila na bakit mababa ang pag-unawa ng mga mag-aaral bago bumasa dahil wala pa silang ideya sa teksto. Naniniwala ang mananaliksik na sa bahaging ito ay isa sa mga indikador na may kakayahan sa pag-unawang kritikal at inferensiyal ang mga mag-aaral. Sa antas ng pag-unawang ito, mapipilitang mapag-isip ang mga mag-aaral sa sitwasyon. Nagpapahiwatig lamang ito na ang tatlong hakbangin ng pagbasa ay dapat parehong bigyang atensiyon ng mga guro.

\section{Mga natuklasa}

Batay sa pagsusuri ng pag-aaral na ito natuklasan ang mga sumusunod:

$>\quad$ Mas mataas ang grade point average ang mga lalaki kaysa mga babae;

$>$ Ang kakayahan ng mga mag-aaral sa kritikal at inferensiyal na pag-unawa sa stages ng pre-reading ay may 2.49 na mean o satisfactory kung saan ang elementong clarity ang nangunguna na may deskriptibong very satisfactory. Mataas ang performance ng mga mag-aaral sa during reading na may very satisfactory ang nakuhang deksripsiyon. At sa post reading outstanding ang performance ng mga kalahok. Ang elementong clarity ay nangunguna sa lahat ng stages at ang elementong logic ang may pinakamababang performance.

> Ang kakayahan ng mga mag-aaral sa pre-reading, na napabilang sa below average ang nakakuha ng mataas na kakayahan na may 2.58 na mean. Ito ay sinundan ng above average (3.51), at ang panghuli ay ang mga mag-aaral na napabilang sa average na may 2.41 na mean. Sa during reading nangunguna ang mga mag-aaral na napabilang above average. May 3.18 na mean at sinundan ng mga mag-aaral na nasa average na may 3.10 na mean at ang mga mag-aaral na nasa below average ay may pinakamababang mean (2.79). Sa post reading nangunguna ang mga mag-aaral na nasa above average, sinundan ng mga mag-aaral na nasa average at ang may pinakamababang mean ay ang mga mag-aaral na nasa below average.

> May kaibahan ang kakayahan ng mga mag-aaral sa kasarian at grade point average at walang kaibahan ang kakayahan ng mga mag-aaral sa tatlong hakbang ng pagbasa na kahit tumaas ang marka o kakayahan ng mga kalahok ngunit hindi masyadong mataas ang pagtaas ng kanilang kakayahan.

$>\quad$ Isang Supplemental Learning Material ang nabuong awtput

\section{Konklusyon}

Ang lohikal na kakayahan sa pag-unawa ay ang pangunahing dahilan kung bakit mababa sa pag-unawa ng kritikal at inferensiyal na kakayahan ng mga mag-aaral.

\subsection{Rekomendasyon}

Batay sa mga nakuhang datos o natuklasan sa pag-aaral na ito, iniharap ang mga sumusunod na rekomendasyon o mungkahi: 
> Dahil nagtamo ng satisfactory lamang ang kakayahan ng mga mag-aaral sa pag-unawa ng pagbasa sa pre-reading na stages kailangan ang puspusang paglinang nito upang makamtam ang kahusayan sa antas ng kritikal at inferensiyal na pag-unawa.

$>\quad$ Ang guro ay gumawa ng mga estratehiya upang malinang ang kakayahan ng mga mag-aaral na makapag-isip, makapagsalita at makapagsulat sa anumang uri ng pakikipagtalastasan.

$>\quad$ Gamitin ang nabuong supplemental reading material bilang awtput ng pag-aaral

\section{Talasanggunian}

Antoniou, F., \& Souvignier, E. (2007). Strategy instruction in reading comprehension: An intervention study for students with learning disabilities'. Learning Disabilities: A Contemporary Journal, 5(1), $41-57$.

Cekiso, M. (2012). Reading comprehension and strategy awareness of Grade 11 English second language learners. Retrieved from https://rw.org.za/index.php/rw/article/view/23/31 https://doi.org/10.4102/rw.v3i1.23

Flippo, R. F., \& Schumm, J. S. (2009). Reading tests. In R. F. Flippo \& D. C. Caverly (Eds.), Handbook of college reading and study strategy research (2nd ed., pp. 408-464). New York, NY: Routledge.

Graham, S., \& Harris, K. H. (2012). The role of strategies, knowledge, will and skills in a 30-year program of writing research (with homage to Hayes, Fayol, and Boscolo). In V. W. Berninger (Ed.), Past, present, and future contributions of cognitive writing research to cognitive psychology (pp. 177-196). New York: Psychology Press.

Green, L., \& Roth, K. (2013). Increasing inferential reading comprehension skills: Single case treatment study. Canadian Journal of Speech-Language Pathology and Audiology, 37(3), 228-239.

Haque, M. (2010). Do-pre-reading activities help learners comprehend a text better [Doctoral dissertation]. BRAC University.

Hirsch, E. (2003). Reading comprehension requires knowledge-of words and the world: Scientific insights into the fourth-grade slump and the nations stagnant reading comprehension scores. American Educator, 27(1), 10-22, 28-29, 44, 1.

Huxley, A. (1984). Retrieved from https://www.brainyquote.com/quotes/aldous_huxley_122020

Kispal, A. (2008). Effective teaching of inference skills for reading literature review. National Foundation for Educational Research. Retrieved from http://files.eric.ed.gov/fulltext/ED501868.pdf

Kurtz, M. (2007). Learning to improve: Using writing to increase critical thinking performance in general education biology. CBE Life Science Education, 6(2), 140-154. https://doi.org/10.1187/cbe.06-11-0203

Medina, S. L., (2011). Effects of strategy instruction in an EFL reading comprehension course: A case study. Profile, 14(1), 79-89.

Monter, J. (2016). Non-tekswual na pagsasanay sa paglinang ng 21st century skills [Di-nailathalang tesis]. Southern Leyte State University-College of Teacher Education, Tomas Oppus, Southern Leyte.

Pabuaya, A. (2014). Pagsusuri sa pagkamalikhain at pagkakritikal sa kakayahang pasalita ng mga mag-aaral [Di-nailathalang Tesis]. Southern Leyte State University-College of Teacher Education, Tomas Oppus, Southern Leyte.

Paul, R., \& Elder, L. (2009). The miniature guide to critical thinking: Concepts and tools (6th ed.). Dillon Beach, CA: Foundation for Critical Thinking.

Pelegrino, R. (2010). Paglinang sa pagkamalikahin at pagkakritikal sa pag-unawa (hots) ng mga mag-aaral sa New Guinsaugon national high school: Dulog modyular [Di-nailathalang Tesis]. Southern Leyte State University- Southern Leyte State University-College of Teacher Education, Tomas Oppus, Southern Leyte.

Pia, M. (2011). Antas na pag-unawa ng mga ideya ng mga mag-aaral gamit ang dulog mass media

[Di-nailathalang Tesis]. Southern Leyte State University-College of Teacher Education, Tomas Oppus, Southern Leyte.

Rusaban, J., et al. (2017). Kritikal at inferensyal na kakayahan sa pagbasa ng mga mag-aaral ng BSIT at BSBA

60 Consortia Academia Publishing (A partner of Network of Professional Researchers and Educators) 
Kritikal at inferensyal na kakayahan sa pagbasa ng mga mag-aaral sa larangan ng Filipino ng VSU

[Di-nailathalang Pamanahong]. Southern Leyte State University-College of Teacher Education, Tomas Oppus, Southern Leyte.

Tagalog, I. (2015). Kakayahan ng mga mag-aaral sa pagsulat ng dula batay sa pag-unawa ng maikling kwento [Di-nailathalang Tesis]. Southern Leyte State University-College of Teacher Education, Tomas Oppus, Southern Leyte.

Tizon, M. (2013). Reading comprehension ability of grade 6 pupils of Kinangay Sur elementary school. In the Proceeding of the global summit on education (pp. 252-262). Kuala Lumpur: World Conference.

Villacruz, A. (2016). Ang mapanuri o kritikal na pag-unawa sa mga modelong akda. Retrieved from https://prezi.com/7vumy0uniho9/ang-mapanuri-o-kritikal-na-pag-unawa-sa-mga-modelong-akda/

Wallace, O. (2007). A study of gender differences in academic performance in a rural county in Tennessee. East Tennessee State University. Retrieved from http://www.171english.cn/htm1/literacyTerms/WhatIsAnInteractiveReadingMode.htm

Yamson, E., (2017). Metakognitibong estratehiya sa paglinang ng kakayahan sa pagsulat [Di-nailathalang Tesis]. Southern Leyte State University-College of Teacher Education, Tomas Oppus, Southern Leyte. 
Flores, M. S.

62 Consortia Academia Publishing (A partner of Network of Professional Researchers and Educators) 